\title{
Un episodio español en la Guerra de los Treinta Años: la embajada del marqués de Cadreita al Sacro Imperio y el acercamiento al Elec- tor Sajón (1629-1631)*
}

\author{
Fernando Negredo del Cerro \\ Universidad Carlos III de Madrid
}

RESUMEN: En 1629, aprovechando el viaje de la infanta María para contraer matrimonio con el hijo del Emperador - el futuro Fernando III-, la Monarquía Hispánica envió al Sacro Imperio un nuevo embajador: don Lope Aux Díez de Armendáriz, I marqués de Cadreita, para cubrir la vacante de ordinario que había dejado en aquella corte el marqués de Aytona tras su marcha a Flandes. Su misión parecía que no iba más allá (y asi lo ha entendido hasta ahora la historiografia) de reforzar la posición española en Viena colaborando con el resto de agentes allí desplazados. Sin embargo, nuestra investigación pretende mostrar que, al precipitarse los acontecimientos tras los sucesos de Ratisbona, el principal negocio al que acabó yendo don Lope no fue otro que el de intentar reconducir las relaciones con Sajonia, acudiendo incluso a Dresde, si era necesario, para impedir que la política intransigente de Fernando II provocase el acuerdo del Elector luterano con Gustavo Adolfo. Los pormenores de esta embajada son el centro del presente artículo, no por un prurito de erudición, sino porque creemos que, el desconocimiento de éste y otros episodios similares muy alejados de la imagen tradicional de la España del siglo XVII, distorsiona enormemente la percepción de la Guerra de los Treinta Años y del papel desempeñado en ella por la Monarquía Católica.

Palabras clave: Lope Aux Díez de Armendáriz; Juan Jorge de Sajonia; Felipe IV; Olivares; barón Echayde Paradis; relaciones internacionales; siglo XVII.

* Abreviaturas de Archivo: Archivo de Cuéllar, Duques de Alburquerque (ACDA), Archivo General de Palacio, Madrid (AGP), Archivo Hsitórico de Protocolos Notariales, Madrid (AHPNM), British Library (BL), Consulta del Consejo de Estado (CCE), Archivo General de Simancas (AGS), Archivo Histórico Nacional (AHN), Real Academia de la Historia (RAH), Archivo General de Indias (AGI), Biblioteca Nacional (BN). 
A Spanish Episode of the Thirty Years war: The Embassy of Marquis of Cadreita near Holy Roman Empire and the approach to the Elector of Saxony (1629-1631)

ABSTRACT: In 1629, taking advantage of the trip to the Infanta Maria to marry the son of Emperor Ferdinand III-future, the Spanish Monarchy Holy Empire sent a new ambassador: Don Lope Aux Diez de Armendáriz, Marquis Cadreita I, to cover the ordinary vacancy in that court had left the Marquis de Aytona following his move to Flanders. Their mission seemed to not go beyond (and so far has understood historiography) to strengthen the Spanish position in Vienna collaborating with other agents posted there. However, our research aims to show that, to rush events in the aftermath of Regensburg, the main business that ended up going Don Lope was no other than to try to redirect the relations with Saxony, Dresden possibly using, if necessary, to prevent uncompromising policy of Ferdinand II provoke agreement with Gustavus Adolphus Lutheran Elector. The details of this embassy are the focus of this article, not for a scholarship itch, but because we believe that the lack of this and other similar events far removed from the traditional image of the seventeenth-century Spain, greatly distorts the perception of the Thirty Years War and the role played in it by the Catholic monarchy.

Key words: Lope Aux Díez de Armendáriz; John George; Philip IV; Olivares; Baron Echayde Paradis; International Relations; XVII Century.

\section{INTRODUCCION}

E1 23 de febrero de 1630 Su Majestad Católica Felipe IV firmaba en Madrid las instrucciones definitivas para su nuevo embajador ante el Emperador, el marqués de Cadreita, quien había iniciado su viaje hasta el Sacro Imperio formando parte del séquito de la reina de Hungría, la infanta María, unos días antes. Una vez allí y siempre según este documento, su papel sería el de ordinario en sustitución del marqués de Aytona, fiel servidor desplazado a Flandes ante la falta de cabezas en aquellos territorios. El contexto internacional, el personaje y los pormenores de la embajada (muy breve, pues en 1631 don Lope obtuvo licencia para regresar a España) nos parecen lo suficientemente interesantes como para detenernos en ellos y acercarnos a un conflicto de enorme complejidad como fue la Guerra de los Treinta Años, acontecimiento central del siglo XVII y eslabón final de la cadena de enfrentamientos religioso-políticos que habían sacudido el Sacro Imperio desde la tercera década del Quinientos y que presenta, aún hoy en día, facetas en penumbra y aspectos no siempre esclarecidos. En esta línea, la participación española en la misma creemos que necesita de una profunda revisión en la que se enlacen los indudables avances de la historiografía hispana y el hispanismo con las interpretaciones clásicas predominantes, demasiado marcadas, a nuestro parecer, por un 
sesgo, aun sin pretenderlo, no tanto hispanófobo como, sencillamente, ignorante total del papel de la Monarquía Hispánica, a la que se suele atribuir, sin más, un decidido apoyo a la causa católica y acervadas veleidades bélicas e imperialistas, convirtiendo al conde duque de Olivares en un ambicioso personaje, tirano de su rey y, decididamente, oscurantista ${ }^{1}$.

Aunque con excepciones, como es lógico, esta visión (más o menos matizada) ha presidido gran parte de la literatura europea sobre el conflicto - no, claro está, la específica sobre España- y ha distorsionado, creemos, el poder valorar en su justa medida las disposiciones tomadas al respecto en Madrid.

El objetivo de este artículo no es, por supuesto, pretender rebatirlas, ni siquiera explicar el porqué de su gestación y desarrollo — vinculado a las corrientes historiográficas dominantes desde fines del siglo XIX cuando España era, entonces sí, una nación marginal en el concierto europeo y Alemania un estado recién construido - sino mostrar, a través de un ejemplo concreto - una embajada al Sacro Imperio - cómo la política de los Habsburgo madrileños defendió siempre la necesidad del acercamiento católico al elector sajón e intentó convencer a Viena de lo temerario de seguir ciertas directrices impulsadas por los jesuitas y diseñadas en Roma en connivencia, se temía, con Munich e incluso París.

Es, por tanto, una necesidad de renovación historiográfica la que nos mueve a rescatar episodios como el que aquí analizaremos pues, a través de ellos, intentaremos calibrar en su justa medida qué papel jugó el régimen olivarista en este conflicto ${ }^{2}$.

\section{EL CONTEXTO 3}

A finales de los años 20 del siglo XVII la posición internacional en que se desenvolvía la Monarquía Hispánica atravesaba un momento crítico (marasmo interdecenal la ha calificado un historiador moderno ${ }^{4}$ ). Una desafortunada

1 Dos ejemplos — de entre los muchos que se podrían traer a colación — pueden ilustrar esta aseveración. Así, en MANN, 1988: 239, leemos: «En realidad, el emperador, rodeado de españoles ansiosos de guerra, frailes y jesuitas, no tenía noción clara de sus propios intereses»; y en KRUMENACKER, 2008: 76 «Avec lui [Olivares], c'est le parti favorable à la guerre aux côtés de l'Empire qui prend le pouvoir, dans l'espoir de redonner tout son rang a l'Espagne».

2 Sobre interpretaciones del conflicto y necesidad de renovación puede leerse WILSON, 2008: 554-586 donde, ahondando en lo dicho, se obvian todas las aportaciones de la historiografía hispana cosa que no sucedía en POLISENSKY, 1978. No obstante el valor de esta obra, el paso del tiempo ha dejado muy superadas sus referencias.

3 Una visión de conjunto donde se aúne la política exterior e interior del momento en ELLIOTT, 1990: 386-437. Para el tema específico de las relaciones con el Imperio y un esbozo biográfico de los principales protagonistas, ALDEA VAQUERO, 1991, 2: XVIII-CXXVIII.

4 ALCALÁ ZAMORA, 2001: 243. 
guerra en Italia - Mantua - y unos Países Bajos obedientes al borde de la sublevación colocaban a Olivares en una situación de extrema debilidad, acrecentada por la pérdida de la flota del almirante Benavides y la falta absoluta de confianza en el entorno cortesano como habían demostrado los acontecimientos del verano de $1627^{5}$. Ante tan compleja realidad, el reforzamiento de la alianza con Viena se antojaba clave para poder salir airosos de los diferentes escenarios. Sólo la comprometida cooperación ayudaría a salvar la crisis y, si con ella se obtenía la participación de la Liga Católica, entonces sí, la situación se podría reconducir en beneficio de las armas de Felipe IV. La idea barajada por el gobierno de Madrid se cimentaba en que Fernando II participara de los mismos objetivos antifranceses y la Liga colaborase en la contienda flamenca con el argumento, cierto, pero casi siempre ignorado, de que el rey de España, como duque de Borgoña, formaba parte del Sacro Imperio (de hecho ostentaba el título de presidente del círculo borgoñón) y su guerra contra los holandeses no era sino la rebelión de unos vasallos felones y herejes ${ }^{6}$.

No obstante, estos presupuestos chocaban con, al menos, cuatro enormes dificultades a la hora de llevarse a la práctica: en primer lugar, porque parecía claro que para que las armas imperiales pudiesen desarrollar toda su efectividad en contra del enemigo común - Francia - se antojaba necesario conseguir una paz estable en Alemania. Algo que la proclamación del Edicto de Restitución entorpecía en gran manera, de ahí los esfuerzos de la diplomacia hispana para que se suspendiese o amortiguase, con gran enojo de los jesuitas encabezados por el confesor imperial W. Lamormaini ${ }^{7}$. En segundo, los objetivos de la Liga, dominada por Maximiliano de Baviera, no pasaban por un enfrentamiento con los holandeses sino por aumentar su poder frente a los protestantes dentro del Imperio. Y aquí la cuestión del Palatinado y las reservas españolas mostradas en el pasado a que se le concediese al Duque Wittelsbach un voto electoral, tenían muchísimo peso, aunque, con todo, era la falta de liquidez de la monarquía la responsable última de que los príncipes católicos no mostrasen un apoyo más decidido a la causa felipista. El atraso en las pensiones y el impago de prebendas prometidas ocasionaba una tibia respuesta ante las peticiones de colaboración militar ${ }^{8}$. En tercer lugar, la pro-

5 Para la crisis de 1627 véase la nueva edición de ELLIOTT y DE LA PEÑA, 2013: doc. XII y doc. XIII. Para la realidad política, militar y económica en los Países Bajos durante estos años ofrece una acertada visión ESTEBAN ESTRÍNGANA, 2005: passim.

6 Como es bien sabido, Felipe IV era señor del condado de Borgoña (o Franco Condado) pero en la documentación de época aparece siempre como «duque de Borgoña y de Brabante». Estas coordenadas se explican detenidamente en ALDEA VAQUERO, 1986: XLVI-LVIII.

7 Sobre el papel de los padres de la Compañía en este periodo véase BIRELEY, 1981 y 2003. También GUI, 1989 y NEGREDO y VILLALBA, 2015.

8 El atraso en los pagos era, a estas alturas, ingente. Al elector de Colonia se le debían, en julio de 1629, 780.000 reales; al de Tréveris más de 190.000. De la misma forma las pen- 
pia personalidad del duque de Friedland, Albrecht Wallenstein, comandante en jefe, por ahora, de los ejércitos imperiales quien, con su propia opinión de la estrategia a seguir, colaboraba a hacer de las relaciones hispano-imperiales una tarea harto compleja ${ }^{9}$. Por último, la diplomacia papal había experimentado un claro giro anti-español a raíz de los acontecimientos de Mantua e intentaba impedir una actuación imperial en el norte de Italia en beneficio claro de las armas francesas ${ }^{10}$.

En este contexto, Olivares y con él Felipe IV, quizá confiados por los triunfos de la Liga y Wallenstein sobre los daneses, prefirieron potenciar la acción diplomática en Flandes que en el Imperio. De hecho, se decidió que don Francisco de Moncada, III marqués de Aytona, se trasladase de Viena a Bruselas como embajador ordinario en sustitución del malquisto cardenal de la Cueva. Su vacante debía ser cubierta en breve por el marqués de Mirabel que, a la sazón, ocupaba la legación en París. Mientras, y teniendo en cuenta la delicada situación en el norte de Italia, se ordenaría enviar junto al emperador tanto a Nicolás Cid, veedor general del ejército de Lombardía, como a Octavio Villani, letrado milanés que acabará siendo un agente clave en la negociación con Alemania. Además, para reforzar el operativo, se destinó al conde de Castro a tierras austriacas como embajador extraordinario con «ocasión de los movimientos presentes de Italia» ${ }^{11}$.

Tamaño trasvase de agentes redundó en una pérdida muy marcada de capacidad operativa, en especial desde el momento en que Aytona emprenda su viaje, Castro obtenga licencia para marchar y todavía no se haya nombrado en firme un embajador de peso ya que, a finales del verano, alarmados ante las noticias que llegaban de Flandes, se había decidido que Mirabel acudiera primero junto a la Infanta en tanto se personaba en aquella corte el de Moncada. Esta debilidad del entramado diplomático hispano en Viena coincidió con el momento de máxima expansión de un «partido antiespañol» alrededor

siones a los diferentes ministros de Fernando II también acumulaban años de impagos. AGS Estado, legajo 2510 «Memoria de todos los pensionarios que hay vivos, lo que tienen cada año y lo que se les debe hasta fin de junio de 1629»» realizada por el conde de Oñate y enviada a Madrid el 29 de agosto. GÜNTER, 1908: 231-233. Vid. también, BL Add. 14.004, nº 112.

9 La personalidad de Wallenstein ha dado lugar a ríos de tinta desde SCHILLER a PARKER pasando por BELADIEZ, 1967 a MANN, 1978 (por citar dos biografías en español) y todas las historias de la Guerra de los Treinta Años dedican numerosas páginas a su figura. Véanse al respecto POLISENSKY, 1978: 130-154 o WILSON, 2009: 391-409.

10 Para el conflicto de Mantua y sus consecuencias remitimos a tres trabajos muy diferentes: FERNÁNDEZ ÁLVAREZ, 1955, STRADLING, 1986 y RAVIOLA, 2011. Para autores como VISCEGLIA, 2004: 185, este problema sucesorio fue el detonante final de la alianza entre los Barberinos y París.

11 Todo este trajín así como las decisiones del Consejo de Estado se pueden leer en AGS Estado, legajo 2329. 
de Fernando II encabezado por el confesor imperial y la propia emperatriz muy enojada por el asunto mantuano. Un tímido alejamiento de los asuntos de estado del príncipe de Eggenberg, valido del emperador y fiel aliado de la política madrileña permitió la implementación del Edicto de Restitución (promulgado en marzo de 1629) a pesar de las continuas advertencias de sus funestas consecuencias que desde España se hicieron ${ }^{12}$.

No obstante, dos acontecimientos programados, en breve, habrían de exigir un despliegue de personal mayor: la boda de la infanta con el hijo del emperador y la convocatoria de una dieta imperial en Ratisbona, a celebrar en el verano de 1630. Ante todo ello el Consejo de Estado, tras diferentes reuniones, aconsejó que se dejase a Jacques Bruneau a cargo de la embajada en tanto llegase la persona elegida y se ordenase al duque de Tursi y a don Carlos Doria viajar con suma celeridad hacia aquellas tierras. El primero, con orden de acudir a los esponsales de la infanta y representar al rey en la Dieta; el segundo, como enviado extraordinario a esta misma reunión. En su respuesta el rey aprobó ambos nombramientos y ordenó, además:

Se me consulten personas que vayan a Alemania a la embajada [...] Los sujetos para esta embajada me enviarán los del Consejo de Estado de su mano y cada uno en su casa y en pliego a mis manos.

No he localizado estas propuestas pero alguna de ellas (¿la de Olivares?) debió ser lo suficientemente convincente como para que se nombrase por embajador a un noble que hasta entonces no había aparecido en ningún papel al respecto y que bien poco tenía que ver con Alemania: aparece así, ya a principios de diciembre de ese mismo año, la figura del marqués de Cadreita ${ }^{13}$.

\section{EL PERSONAJE}

Don Lope Díez Aux de Armendáriz, I marqués de Cadreita14 no ha sido un personaje tratado en profundidad por la historiografía, si bien tampoco es un desconocido. Su faceta como marino y, sobre todo, la de virrey en Nueva Es-

12 Ya al poco de su publicación Aytona escribía a Madrid informando de las nefastas consecuencias de esta política pues los príncipes desposeídos solicitaban la ruina de la Casa de Austria y como él decía «el decreto para la restitución ha sido con muy mala sazón de que hacen autores a los jesuitas» CCE, 18 de octubre de 1629. A.G.S. Estado, legajo 2329.

13 La orden de Felipe IV (AGS Estado, legajo 2.329) es de 23 de octubre de 1629. La primera referencia que he podido localizar de Cadreita como embajador es de 4 de diciembre de ese año. Según AMADORI, 2011: 113, nuestro hombre pertenecía a la facción olivarista y de ahí su presencia en la Junta de Guerra de Indias donde se sentaban otras hechuras del privado.

14 La grafía del topónimo navarro de Cadreita puede aparecer, indistintamente, como Cadereita, Cadereyta o Cadreyta en la documentación de época. 
paña pueden rastrearse en la producción científica pertinente ${ }^{15}$, pero, que sepamos, nadie ha abordado su labor como embajador al Sacro Imperio y, lo que es más importante, tampoco se ha detenido en explicar el fulgurante ascenso social de este indiano que, de hijo de oidor, llegará a suegro de Grande ${ }^{16}$.

En efecto, don Lope nació en Quito hacia $1575^{17}$ siendo el quinto de ocho hermanos dentro de una rama colateral de los señores de Cadreita, señorío amayorazgado en 1503 por sus bisabuelos, Jaime Aux de Armendáriz y Leonor de Veráiz y ubicado en el reino de Navarra ${ }^{18}$. Sin embargo, las condiciones estipuladas por los fundadores (mayorazgo agnaticio) y la evolución biológica, hicieron que la herencia del señorío acabase recayendo en nuestro protagonista previamente enviado a la Península a educarse con su abuela paterna, Inés de Castrejón, en su casa solariega de Ágreda ${ }^{19}$. Su padre, que

15 Para el primer aspecto, FERNÁNDEZ DURO, 1895: t. IV; el segundo puede seguirse, entre otros, en HANKE, 1977: 9-23, ISRAEL, 1980: cap. VII o ÁLVAREZ DE TOLEDO, 2011: passim.

16 Hay noticas dispersas sobre él también en BARRIO GOZALO, 1998 y ANDRÉS TOVAR, 1956 sobre los que volveremos.

17 Los datos de su nacimiento los da él mismo en su expediente para caballero de Santiago incoado en 1605 (AHN Órdenes Militares, exp. 2481) en donde varios testigos afirman que era mayor de 30 años, mientras que otros le calculan una edad de entre 26 y 28 . Estos datos ya los cotejó LOHMANN VILLENA, 1993: 135, por eso no entiendo muy bien el porqué de las afirmaciones que al respecto hace su último biógrafo como hacerle nacer en Sucre. (Vid. Diccionario Biográfico Español de la RAH, t. XVI: 309-311).

18 El señorío de Cadreita fue concedido en 1446 por el príncipe de Viana (y confirmado por Juan II en 1450) a Jaime Díez Aux, padre del fundador del mayorazgo. Cfr. BARRIO GOZALO, 1998: 198.

19 La relación entre los Díez Aux de Armendáriz y los Castrejón se inició a principios del siglo XVI y daría, con el tiempo, réditos políticos. Inés casó con Luis Díez Aux de Armendáriz en 1514 mientras que una hermana de él, Isabel, realizó lo propio con un hermano de ella -Juan González de Castrejón-. Éstos últimos serán los abuelos de Diego de Castrejón y Fonseca, presidente del Consejo de Castilla entre 1640-43. Por otra parte, para entender cómo llegó a cabeza de nuestro biografiado el título de señor de Cadreita hay que conocer la genealogía de la familia. Siendo muy sucintos digamos que de su abuelo, don Luis, el señorío pasó a su único tío paterno de igual nombre quien al tener sólo hijas - un vástago homónimo falleció en temprana edad - decidió, aprovechando que su primogénita había quedado viuda del marqués de Falces, casarla con su primo, esto es, el hermano mayor de don Lope, Sancho Díez Aux de Armendáriz quien, legalmente, estaba llamado a ser el V señor de Cadreita. De este enlace no hubo hijos por lo que, cuando Sancho falleció en 1612, el título pasó al siguiente hermano, Gonzalo, quien sin tener descendencia murió en 1615 por lo que fue entonces cuando don Lope, siguiente varón supérstite, heredó el título. Es por tanto el futuro marqués el VII señor de Cadreita y recibió el título vía su tío y hermanos, no a través de su padre que nunca lo poseyó. Sería demasiado prolijo detallar todos los documentos en los que nos hemos basado para esta reconstrucción genealógica que complementa y, en algunos casos corrige, a BARRIO GONZALO, 1998: 199 y ANDRÉS TOVAR, 1956: 348, muchos de ellos, además, citados por estos autores, sólo reseñamos a continuación tres que nos parecen claves : ACDA, caja 128, leg. 9, exp. 2b «Inventario de los bienes muebles y otras cosas de don Gonzalo Díaz 
había sido oidor en la Audiencia de Charcas, alcalde de la cuadra de Sevilla, presidente de la Audiencia de Quito, presidente de la Audiencia de Charcas y, por fin, presidente en la de Santa Fe y gobernador y Capitán General del reino de Nueva Granada ${ }^{20}$, había casado con Juana de Saavedra y Recalde cuyo hermano, don Fernando de Saavedra, introdujo a nuestro don Lope en el servicio real ya que fue su teniente todo el tiempo que éste gobernó la caballería de Languedoc ${ }^{21}$. Sin embargo, no era la guerra en tierra la que atraía al futuro marqués sino la mar y desde 1599 se le localiza embarcado en diferentes flotas en dirección a América alcanzando en 1602 el grado de almirante y en 1606 el de general de la flota. Al menos veinte veces cruzó don Lope el Atlántico, bien al mando de la escuadra de Nueva España, bien como general de la armada de la guarda de Indias con destino en Tierra Firme y en todos ellos cumplió el importante encargo de traer la plata a salvo lo que valió el reconocimiento de la administración y, según parece, una importante inyección de dinero no siempre dentro de la legalidad 22 . El caso es que con un nombre ya hecho en el mundo indiano y con rentas saneadas inició una brillante carrera cortesana siendo nombrado caballero de Santiago en 1605, gentilhombre de la boca en 1614 y mayordomo de Felipe IV quince años después $^{23}$. En el ínterin había recibido el señorío de Cadreita - una vez fallecido su hermano Gonzalo-y había sido designado marqués $(1617)^{24}$.

Aux de Armendáriz, señor de Cadreita, por ante Pedro de Agramonte y Zaldívar. 21 de octubre de 1615»; RAH Salazar y Castro, D.21, fol. 169v «Costados de Lope Diez Aux de Armendáriz y Saavedra González de Castejón y Recalde, I marqués de Cadreita» y AHN SN (Toledo) Ovando, 3893 «Árbol de la Ilma. Casa de los señores marqueses de Cadreita»

20 Elección como oidor de las Charcas - 2 de julio de 1557- en A.G.I. Indiferente, 738, n.7. Nombramiento como presidente de la Audiencia de Quito - 30 de julio de 1568 - en Idem, Quito, 211, Lib. 1, fol. 165r. Embarcó para América en enero de 1569 acompañado de su mujer y cuatro de sus hijos, los citados Sancho y Gonzalo y dos féminas, Inés y Francisca. Hasta ese momento era juez en la audiencia de Sevilla (alcalde de la Cuadra). Nombramiento como presidente de la Audiencia de Charcas, Idem, Charcas, 415, lib.2, fol.11v-13r. Propuesta del Consejo y aceptación real para ocupar la presidencia del «Nuevo Reino de Granada» en Idem, Indiferente, 738, n.236, 19 de octubre de 1576.

21 AGI Patronato, 254, n.1, g.11, r.1.

22 Los datos de su carrera proceden de AGI Patronato, 254, n. 1, g.11, r.1, con un memorial de sus servicios. En el mismo archivo, Contratación, leg, 2980, con una relación de todos sus viajes desde 1606 a 1634 . Indiferente, leg. $745, n^{\circ} 267$, con su propuesta para ir como entretenido en la flota de Nueva España en 1599; Escribanía, 1152A, «Diligencias que se hicieron en Sevilla en 1616 para la cobranza de las condenaciones que se impusieron a los generales ... marqués de Cadereyta». Véase también HANKE, 1977: 10-11.

23 AGP Exp. Pers. 157/33 y Administrativa, legajo 644.

24 Hay copias del título en ACDA caja 119, leg. 2, exp. 2 y exp. 37. Por otro lado, aunque no tengo pruebas fehacientes, ciertos indicios y el contexto permiten sospechar que el marquesado no fue concedido, tan sólo, por los méritos y valía de don Lope, sino que algo tuvieron que ver los pesos peruleros en el ánimo de Felipe III y sobre todo, en los de sus más cercanos 
El ennoblecimiento no trasformó la dinámica vital de Díez Aux de Armendáriz pues continuó ejerciendo su profesión de marino con acierto y fortuna siendo su nombre, casi, garantía de llegada de la flota - y con ella la plata - desde las Indias. En el tránsito entre la segunda y la tercera década del siglo XVII hizo media docena de viajes, con sus respectivos retornos, cesando por el momento sus actividades en 1625 momento en que le documentamos en la corte no volviendo a embarcarse hasta 1633. A partir de esa fecha su carrera es más conocida ya que esta última travesía dio lugar a una investigación y condena ${ }^{25}$ - que no truncó su ascensión - y en 1635 fue designado virrey, capitán general y presidente de la audiencia de Nueva España, cargo que ocupó hasta 1642 en que regresó a Madrid, donde falleció el 9 de febrero de 1644 . Para entonces ya se codeaba con lo más granado de la sociedad madrileña, no sólo por los lazos de parentesco sino también por amistad, de ahí el acompañamiento que llevó su cadáver cuando fue depositado, temporalmente, en el convento de la Merced de Madrid ${ }^{26}$. Y su gran triunfo vino después de muerto - aunque es razonable pensar que lo planificó en vida - ya que el 12 de enero de 1645 su única hija, Juana Francisca, contrajo matrimonio con Francisco Fernández de la Cueva, VIII duque de Alburquerque, entroncando desde entonces su casa de Cadreita con ésta - a pesar de ciertas dificultades posteriores - y desapareciendo, en realidad, a los ojos de los contemporáneos.

Así pues nos encontramos ante un marino con experiencia, encomendero en Indias y todo hace apuntar que saneada hacienda ${ }^{27}$ que, sin que nos sea dado el saber porqué, fue elegido a finales de 1629 para acudir como embajador ordinario a Alemania (en realidad a la corte del emperador del Sacro Imperio, pero en la documentación se le designa así) justo en el momento en que amenazaba aquellas tierras una enorme tempestad.

colaboradores ya que, según un escrito de su abogado defensor de 1634 (vid. nota siguiente) para entonces ya había realizado tres donativos por valor de 16.000 ducados.

25 Juan de Santelices, regente de la audiencia de Sevilla, le tomó residencia de su tornaviaje de 1634 y le halló culpable de 12 cargos condenándole a una desorbitada multa de 31.000 ducados. Como no podía ser de otra manera el inculpado recurrió al Consejo que parece le dio la razón a tenor de su rápido nombramiento como virrey. Véase su apelación en BUCM, F.H. FOA 497(8).

26 Infantado, Híjar, Villena, don Francisco Antonio de Alarcón y «otros muchos señores y caballeros que se hallaron presentes al dicho depósito» acompañaron el féretro de don Lope que fue entregado a los frailes redentoristas por el marqués de Valparaíso, don Francisco de Andía Irazábal. AHPNM, lib. 6219, fol. 766.

27 Desde 1625 gozaba de la encomienda de Cica Cica en el Perú con 4.000 pesos de renta anual a tenor del expediente de confirmación sito en AGI Lima, 201, $\mathrm{n}^{\circ} 1$. Según el documento citado en la nota 26 gastó 50.000 ducados en su embajada a Alemania, además del sueldo, señal de que los tenía pues no hace mención — ni hemos documentado - censos o préstamos significativos sobre sus casas y hacienda, sí un juro a su favor de más de 16.000 reales. AGS CME, 1414, exp. 7. 


\section{LA EMBAJAdA DEL MARQUÉS 1630-1632}

Como ya hemos apuntado, el 26 de diciembre de 1629 salía rumbo a Viena la infanta María con un notable séquito entre el que se encontraba don Lope ${ }^{28}$. La decisión de que viajara con la reina de Hungría había sido aprobada por el Consejo aun a sabiendas de que eso habría de retrasar la llegada a su destino por lo que se decidió, en el ínterin, enviar al duque de Tursi por la posta. Mientras, se pulían las instrucciones que habría de llevar, guía básica de su cometido allá y que le alcanzaron de camino ${ }^{29}$. Resumiendo su contenido - que se completaba con las que en su momento, habían llevado Aytona y Castro-, la estrategia central que debía presidir sus gestiones se articulaba en dos puntos: conseguir del Emperador ayuda efectiva y suficiente contra Francia y lograr que la Liga Católica se involucrase en la guerra de Holanda llegando a prometer, si fuese el caso, las tierras a reconquistar en Frisia. Luego se le daban otra serie de consejos colaterales y se le remitían diversos papeles de los que se habían cursado a los que se situaba como sus más cercanos colaboradores: Tursi y Bruneau ${ }^{30}$. También se le recordaba que Madrid era perfectamente consciente de las deudas que se tenían para con los pensionados y confidentes y que era labor suya aplacarlos (sin dinero) de la misma forma que debía convencer a Baviera y demás electores católicos de que el Palatinado se restituiría al completo en el mismo momento que se firmase una paz general (esto es, incluyendo a Holanda) pero que, mientras tanto, se retenía en prenda de los gastos ocasionados por su conquista y ocupación sin que ello implicara ningún deseo de ocupar nada más en Alemania ${ }^{31}$.

No obstante, la tardanza en alcanzar su destino (catorce meses) y los graves acontecimientos que entretanto sacudieron el Imperio, obligaron a replantear estrategias y a que Cadreita se viese impelido a iniciar una serie de gestiones

28 Sobre este particular, LABRADOR, 2011, vol. II: 801-836. Hay interesante documentación —original- al respecto en BL Add. 14.004.

29 BN Mss 10.818/11. (copia, como la de BL Add.14.004, fol. 457-460), 23 de febrero de 1630. El original de estas instrucciones se encontraba en el ACDA, de donde se sacó el traslado que hemos consultado. No es este espacio para discernir el porqué la mayoría de los papeles concernientes a esta embajada no se encuentran hoy ya en el ACDA (o al menos nosotros hemos sido incapaces de localizarlos). Afortunadamente las copias sí existen en la Biblioteca Nacional de Madrid. El Consejo de Estado discutió el contenido de las instrucciones en consulta del 10 de enero de 1630, añadiendo el rey algunos párrafos a la minuta propuesta. AGS Estado, 2331. Las instrucciones a Tursi, de 1 de febrero de 1630, en BN Mss. 2.362, fol. 1317. Vid. ALDEA, 1986: 349-356 y GÜNTER, 1908: 253-254.

30 Desde el 25 de abril, Jacques Bruneau era oficialmente residente en Alemania con la mitad del sueldo de un embajador ordinario. AGS Estado, legajo 2456.

31 Ni qué decir tiene que el Palatinado ofrecía otra arista que pulir: la relacionada con Inglaterra - Federico $\mathrm{V}$ era yerno de Jacobo I- y en la que no podemos entrar aquí. Para ello véase como encuadre general SANZ CAMAÑES, 2002. 
para las que no había sido aleccionado y que, a tenor de documentación, le acabaron desbordando por lo que muy pronto reclamó insistentemente su regreso a la Península achacando problemas de salud ${ }^{32}$.

En efecto, Don Lope llegó a Viena a finales de febrero de 1631 después de haber pasado por Nápoles y Roma, escala ésta última que no satisfizo al Consejo pero que realizó cumpliendo órdenes de la reina de Hungría ${ }^{33}$. Mientras él se encontraba en tránsito, el equilibrio de poder en Alemania había cambiado sustancialmente ya que la dieta de Ratisbona había consolidado un frente antihabsburgo entre los propios católicos, auspiciado y financiado por Francia. Los tres electorados episcopales y Baviera habían logrado la retirada de Wallenstein e impedido la elección de Fernando como rey de Romanos, mientras los príncipes protestantes leales a Viena no habían acudido en denuncia por la aplicación del Edicto de Restitución ${ }^{34}$. La paz de Ratisbona, «peor que si se hubiera firmado en Constantinopla» marcó uno de los momentos más críticos en la relación entre las dos ramas de la Casa y obligó a un gran esfuerzo de fidelidad por parte de Madrid hacia lo que se consideraba una espantosa traición ${ }^{35}$. Por otro lado, también había demostrado que los ambiciosos planes ideados por don Gaspar y secundados por el Consejo de aislar a Baviera ganándose a Tréveris y Maguncia habían fracasado estrepitosamente $^{36}$ reforzando el papel que debía desempeñar Sajonia que no era otro que el de piedra angular de una nueva configuración geoestratégica pues, ante

32 El 9 de julio de 1631 solicitaba licencia al conde duque para volverse, escribiendo al día siguiente al rey con la misma petición. El monarca resolvía dársela el 29 de agosto, pero Díez Aux de Armendáriz aceptó no usar de ella hasta dejar aquellos asuntos en buenas manos.

33 El Consejo, en reunión de 4 de febrero de 1631, opinaba que: «Le parece que, en ir a Roma como lo refiere en memorial aparte, no ha hecho bien porque allí no le harán la honra que se debe a embajador nombrado por V.Majd. para la corte del Emperador». AGS Estado, legajo 2332.

34 Para un análisis de lo acontecido en torno a la reunión de Ratisbona (Regensburg), vid. PAGÉS, 1949: 123-124; RÓDENAS, 1966: 238-244; BELADIEZ, 1967: 211-223; POLISENSKY, 1974: 180-181; PARKER, 1984: 167-169. BIRELEY, 2003: 105-109 o WILSON, 2009: 454-458.

35 AGS Estado, legajo 2331, CCE 10 de noviembre de 1630. Olivares se lamentaba amargamente de lo que consideraba una traición sin precedentes y postulaba que, de no haber sido inferida por un Habsburgo hubiese merecido una respuesta contundente. Cfr. RÓDENAS, 1966: 243-244 y 266-275. Su contexto en ELLIOTT, 1990: 399.

36 El diseño de la estrategia que debía seguirse en Ratisbona se puede seguir a partir del voto del conde duque con fecha de 1 de julio de 1630 que se discutió en la CCE de 6 de julio de 1630 (consulta, dicho sea de paso, que enojó por su forma a Felipe IV, quien reprendió severamente a los secretarios). En él, el valido, dando muestras de un gran cinismo político, pretendía que los embajadores lograsen la desunión de los electores católicos con Baviera pero sin que este objetivo se filtrase y debían «procurar por indirectas con maña y sagacidad desquiciar aquella autoridad absoluta y independiente del duque de Baviera sobre la Liga Católica dexándola subordinada al Emperador». AGS Estado, legajo 2331. 
la constatación de que Francia inclinaba a los príncipes católicos en contra de los intereses de la Monarquía, se hacía cada vez más acuciante contar con la alianza sajona. Esta es la razón de que se cursase orden a los embajadores en Alemania de que «se podrían valer, si les pareciere conveniente, de su yerno, el langravio de Hassia, afectísimo él y su padre Ludovisio a esta Corona ${ }^{37}$ para distanciar a Juan Jorge de Gustavo Adolfo y que retornase a la órbita de Fernando II $»^{38}$.

Así pues, cuando don Lope (y su mujer) llegaron a la corte imperial las aguas andaban mucho más revueltas de lo que se había imaginado en su partida. Ya no consistía en pretender que Baviera entrase a formar parte de un pacto anti-holandés, sino que había que defenderse de una ofensiva diplomática en toda regla orquestada por Richelieu que iba a conseguir notables triunfos en breve. De hecho, en enero se había firmado el tratado de Bärwalde entre Francia y Gustavo Adolfo de Suecia y a finales de mayo de 1631 el de Fontainebleau entre Maximiliano y Luis XIII. Ambos acuerdos cerraban un círculo antihabsburgo que Madrid debía romper a toda costa si quería mantener sus expectativas de victoria en Flandes y de seguridad en el norte de Italia.

Con este negro horizonte comenzó el flamante embajador su labor. Olivares se daba cuenta ahora de que su elegido quizá no fuese la persona apropiada para el cargo ${ }^{39}$, pero no quedaba más remedio que animarlo a continuar apoyándose en los «prácticos» de aquellos lugares en especial Bruneau y, sobre todo, el padre Quiroga, confesor de la infanta, quien junto al duque de Guastalla, también convocado a Viena, habrían de erigirse en los dos agentes fundamentales en aquellas tierras ${ }^{40}$. Y, por supuesto, hubo que replantearse la

37 Se refiere a Jorge II de Hesse-Darmstadt, hijo de Luis V y casado con Sofía Leonor de Sajonia quien, además, había visitado España con anterioridad.

38 El papel de Sajonia en la Guerra de los Treinta Años ha sido muy debatido por la historiografía. Aunque no podemos detenernos en ello parece como si, para ciertos historiadores germánicos, por el hecho de mantener su lealtad al emperador fuese un traidor a la causa alemana, traición agravada por su condición de luterano. Más equilibrado, GOTTHARD, 1993: 275-319, quien, basándose en documentación de Dresde, llega a la conclusión de que, la obediencia política de Sajonia a las constituciones del Imperio la convirtieron en un territorio «procatólico».

39 De hecho en Consulta del Consejo de Estado de 22 de enero de ese año ya se discutió enviar a Alemania a «un primer espada» pues se presentía que Cadreita no iba a estar a la altura de las circunstancias. AGS Estado, legajo 2332. Los nombres propuestos fueron Feria, Mirabel, D. Gonzalo de Córdoba, Aytona, Castelrodrigo, Alba, Alcalá y Lerma pero ninguno de ellos fue el elegido.

40 El duque de Guastalla fue propuesto por Bruneau como colaborador libre, recomendación admitida por Felipe IV dotándole con la ayuda de costa pertinente (CCE 10 de abril de 1631. AGS Estado, legajo 2332). Su labor, muy aplaudida por Madrid, se truncó, sin embargo, muy pronto ya que enfermó de gravedad a finales de 1631 y falleció poco después. De hecho, a mediados de enero de 1632 tanto Bruenau como Cadreita escribieron al secretario Rozas 
estrategia. Sin olvidarse de las antiguas pretensiones ahora se antojaba urgente ampliar el abanico de aliados.

El Consejo de Estado discutió con profusión qué hacer y, cuando se supo con certeza que la liga franco-bávara había contado no sólo con el beneplácito sino con la participación de los agentes papales, se comenzó a trazar una nueva alternativa. En consejo particular en el aposento del conde duque en marzo de 1631 los máximos expertos de la Monarquía en materias del Imperio - esto es, Oñate, don Gonzalo Fernández de Córdoba y el conde de Castrillo, junto al valido - votaron un plan de actuación que se articulaba en torno a una serie de consideraciones básicas (una vez, por supuesto, realizadas las oraciones $\mathrm{y}$ preces de rigor).

La primera, reforzar la unión con el Emperador (algo que parecía sencillo pues sólo se valoraba un posible escollo, su confesor, W. Lamormaini, a quien convendría ganarse «a cualquier precio» ofreciéndole, incluso, un capelo, si fuere menester) poniendo en marcha una liga defensiva-ofensiva. La segunda, disimular tanto con Baviera como con Maguncia y Colonia llegando a proponer Olivares una posible boda entre la hermana del duque y el infante don Carlos para aproximar a los Wittelsbach y los Habsburgo (punto éste en el que discreparon Oñate y don Gonzalo ratificando Felipe IV la opinión de ambos). En tercer lugar, buscar un acercamiento al elector sajón «el mayor pilar de Alemania» mediante el envío de un embajador a Dresde, política que, dicho sea de paso, también se potenciaba desde la corte al recibir con estimable cortesía a Christian de Osterhausen, gentilhombre del elector que venía a negociar el espinoso asunto de Winnendal, litigio con el duque de Neoburgo y que tenía una vertiente flamenca de difícil solución ${ }^{41}$. En cuanto a los asuntos de Alemania, todos los partícipes en el consejo sabían que Juan Jorge se hallaba «sentido por la reformación de las iglesias de los luteranos» y aunque nadie se atrevía a aconsejar directamente al rey que escribiese a su tío en con-

avisando de las pocas esperanzas que tenían en su salud y que era necesario enviar un nuevo embajador para allá y, como decía el primero «de las partes que otras veces ha representado y no para dos y tres años, sino para diez y quince porque entrará con otro pie, buscando criados a propósito y procederá diferentemente» haciendo una fina crítica de la labor de nuestro protagonista (CCE 18 de marzo de 1632, AGS Estado, legajo 2332). En cuanto al padre Quiroga, gran parte de su correspondencia para estos años se conserva en BL Add. 24.909. Se han ocupado de él — sin explotar a fondo esta fuente-, CARROCERA, 1947: 71-100 y REEVE, 1986: 913-926.

41 Véanse las cartas para el Elector de 28 de mayo de 1630. AGS Estado, legajo 2456. Juan Jorge también había escrito muy cortésmente felicitando a Felipe IV por el nacimiento de un heredero. No obstante el duque de Neoburgo negociaba asimismo exigiendo se cumpliera la sentencia dada por Bruselas en su favor. CCE 6 de junio de 1630. AGS Estado, legajo 2331, pero Madrid prefería, por el momento, contentar al sajón en quien veía un potencial mejor aliado (CCE de 7 de enero de 1632. AGS Estado, legajo 2333). 
tra de tan piadosa resolución, sí que animaban, en especial Oñate, a los embajadores a que hiciesen ver a su Majestad Cesárea qué perseguían, en realidad, los que defendían su implementación (incluido el Papa, a quien también se atacaba). En este sentido todos convenían en creer que era Francia, a través de Baviera, y con el beneplácito de Urbano VIII la gran interesada en su aplicación pues así conseguía «hacer desconfidente al emperador de los herejes» y reducir su poder ${ }^{42}$.

Una vez aprobadas estas directrices por el monarca, se trasladaron a los agentes en el Imperio. Así, en las instrucciones giradas al duque de Guastalla, de 22 de abril de 1631, se le exponían de forma clara todos estos postulados al ordenarle poner en marcha el mencionado acercamiento al elector sajón como primer paso para atraerse a otros príncipes protestantes - en especial Brandemburgo - y potenciar un entendimiento con Saboya y Lorena, territorios muy sensibles ante Francia y, sobre todo en el primer caso, con quien habían surgido ásperas diferencias que se debían limar ${ }^{43}$. Como colofón se le animaba a que moviese una alianza «con los herejes que pareciese a propósito» para la cual se podía tener por cierto que no iban a faltar, según Felipe IV, «mis asistencias de dinero en ocasión y forma conveniente» ${ }^{44}$.

En este mismo sentido, un mes después, en carta a Cadreita, se explicitan claramente las líneas de actuación que debía potenciar: aun admitiendo que el Edicto de Restitución podía ser, en abstracto, muy piadoso, no debía seguir aplicándose por las nefastas consecuencias que en el Imperio generaba y porque, además, su inspiración tenía orígenes espurios ${ }^{45}$. Orígenes que se vincu-

42 CCE 31 de marzo de 1631. AGS Estado, legajo 2332. El voto de Olivares es mucho más rico de lo que aquí, por cuestiones de espacio, extractamos, pues desarrolla también su visión de otros escenarios y la forma de financiar todo el esfuerzo bélico-diplomático.

43 Tras la firma de la paz de Ratisbona, «los ministros del rey, deseosos de tener obligado al de Saboya» ofrecieron la posibilidad de que el duque comprase algunos feudos imperiales en el norte de Italia, iniciativa que Felipe IV desautorizó «considerando el daño que resultaría a ese estado [Milán] de caer en manos del duque los lugares de Novelo, Monforte, Sinio, Monchier y Casteleto». A pesar de ello, los saboyanos continuaron en sus pretensiones, sobornando, según los embajadores españoles, a ciertos consejeros del emperador. Madrid bloqueó de forma radical tales iniciativas añadiendo un elemento más de crispación a las relaciones bilaterales. Hay nutrida información sobre este tema tanto en el legajo 2336 (resumen de la situación a la altura de 1635) como en el 3444 con las cartas enviadas a Cadreita y al gobernador de Milán - Feria - en este sentido.

44 Instrucciones al duque de Guastalla, 22 de abril de 1631. AGS Estado, legajo 2457. Hay copia en BN Mss. 10.8196. GÜNTER, 1908: 276-283.

45 «Siendo hoy el Edicto de Restitución de los bienes eclesiásticos la causa porque se inquieta, en la cual persiste el emperador llevado de su celo y persuadido de los que, con pretexto de piedad quieren irritar contra él a los herejes, es fácil y justo suspender la ejecución del edicto a mejor sazón [...] y estorbar una guerra de religión en el Imperio que si comienza a crecer será de gravísimos daños a la causa católica; y lo que parece piedad y de suyo lo es, por las circunstancias del tiempo y estado presente será incendio del Imperio». AGS Estado, lega- 
laban con el duque de Baviera («el mayor enemigo de la Casa de Austria» ${ }^{46}$ ) a quien convenía debilitar siendo el camino:

quietar y dar satisfacción al duque de Sajonia a condición de que con sus armas y poder y con el de sus parciales asista al emperador y contra cualesquier enemigos suyos públicos y secretos. Y esto no parece difícil de encaminar por ser Sajonia príncipe constante y que se mueve tarde y se halla obligado a la Casa de Austria.

Así pues, en la primavera de 1631 encontramos ya dos elementos clave para nuestra argumentación: se constata que, tanto el rey como su valido, estaban muy lejos de sostener al partido intransigente católico dentro del Imperio como cierta historiografía ha propugnado ${ }^{47}$ y que, al contrario, habían decidido intentar una alianza con los llamados protestantes moderados, principios de actuación corroborados en el Consejo de Estado de 7 de junio y explicitados de nuevo en la correspondencia a don Lope doce días después ${ }^{48}$.

Ahora bien, la empresa se antojaba de una envergadura tal que demandaba hombres de gran experiencia diplomática y en plenitud de facultades. Justo lo que no había en Viena.

En efecto, sabemos por la correspondencia privada de nuestro marqués que los fuertes «dolores de hijada» le mantenían casi inactivo y, aunque intentaba continuar operativo, sus informes dejaban bastante que desear, para desespe-

jo 2457. Carta de Felipe IV al marqués de Cadreita, 28 de mayo de 1631. GÜNTER, 1908: 285-6.

46 La actuación política de Maximiliano de Baviera ha sido estudiada en diversas monografías alemanas como ALBRECHT, 1962 o KRAUS, 1990, que a veces rozan la hagiografía. Por eso levantó tantas ampollas entre la historiografía bávara el libro de Straub, donde podemos leer que Maximiliano desempeñó un papel funesto para la política alemana pues era un príncipe que sólo perseguía sus propios objetivos «sin que le importaran, ni el Imperio, ni el emperador ni la paz en Europa» STRAUB, 1980: 474-475. Este libro tiene la ventaja, frente a los precedentes, de utilizar profusamente la documentación de Simancas.

${ }^{47}$ A este respecto no deja de ser llamativo que, mayoritariamente, se identifique a los jesuitas con la política de Madrid cuando, precisamente, fueron ellos los máximos responsables del fracaso de las iniciativas gestadas por Olivares y Felipe IV para con el Imperio. Véase a este respecto, BIRELEY, 2003: passim y más en concreto, NEGREDO y VILLALBA, 2015.

48 La consulta en AGS Estado, legajo 2332 donde leemos opiniones particulares como «con la negociación procurar ganar a Sajonia y Brandemburgo (Olivares)» o «Convendría ganarle o no exasperarle [al de Sajonia] persuadiendo V. M. al emperador que por ahora no apriete, antes disimule, en la restitución de los bienes eclesiásticos, pues lo puede hacer (Sotomayor)». Las cartas a Cadreita de 19 de junio en Ibidem, legajo 2457 en las que se le dice, entre otras cosas: «El de Sajonia es príncipe constante y ha seguido las conveniencias del emperador y de nuestra casa. Y aunque el Edicto de Restitución de los bienes eclesiásticos puede haber turbado algo la buena inteligencia con que ha corrido hasta aquí, como el emperador esté persuadido de que moderar en la ejecución de él el fervor de su piedad es el mayor servicio que se puede hacer a la religión católica en el estado presente ... se puede esperar que el elector de Sajonia se reducirá sin mucha dificultad». 
ración del Consejo de Estado ${ }^{49}$. Desde Madrid se le acusaba de dilapidar el dinero y no saber negociar con el rigor y la diligencia necesarios y se le recriminaba su casi total desconocimiento de la realidad alemana, más allá de la corte imperial. No obstante estas críticas, tras recibir las cartas recién citadas puso en marcha una operación que nos atrevemos a calificar de audaz, si bien no estamos en condiciones de asegurar partiera de él o respondiera a instrucciones secretas recibidas desde el Alcázar y que los propios miembros del Consejo desconocían. El caso es que, de hacer caso a sus palabras, decidió girar visita ese verano a Juan Jorge de Sajonia y, ante la imposibilidad física de hacerlo, comisionó a un tercero, el barón don Enrique Paradís de Echayde, para que fuese en su lugar.

Y aquí nos gustaría incluir una pequeña digresión sobre la capacidad real del Consejo de Estado a la hora de enfrentarse a situaciones como la que estamos tratando. Por un lado, no es extraño encontrar en las fuentes quejas sobre no tener referencias ciertas sobre lo que opinar ${ }^{50}$, mientras que, por otro, la tardanza en los correos - aún cuando no se perdiera ninguno- hacía inviable en numerosas ocasiones el cumplimiento de las órdenes debido a la mudanza de la realidad. Con este telón de fondo debemos analizar la práctica diplomática de Cadreita y no caer en la censura fácil — como a veces se hizo desde Madrid-. Censura que, por otra parte se extendería a toda su gestión y que le seguiría hasta su retorno a la capital pero que, sin embargo, no invalidaría su nombramiento como virrey de Nueva España que tenía conferido aunque no certificado - desde antes de su partida hacia Alemania.

Volviendo a la embajada (de la que tenemos un buen resumen realizado por su artífice ${ }^{51}$ ) el Consejo tuvo noticia de ella por carta de 26 de septiembre del barón Paradís al secretario Andrés de Rozas (recibida en la corte a principios de noviembre) en la que daba cuenta de la derrota de Tilly (Breitenfeld) y enviaba copia de las instrucciones proporcionadas por Cadreita. Más ade-

49 Sus dolencias, muy posiblemente cálculos renales, son descritas pormenorizadamente en su correspondencia particular, por ejemplo, ACDA Varios, leg. 371, exp. 1, carta de Doria a Cadreita, 7 de julio de 1631. Las quejas sobre su mala gestión las resumió el secretario Rozas en un papel que puede leerse en AGS Estado, legajo 2332, sin fecha, pero de julio de 1631 .

50 Quizá el texto más claro sea el voto de don Gonzalo de Córdoba en el Consejo de 19 de noviembre de 1631 cuando afirmó que frente a las frecuentes noticias de la corte cesárea sentía mucho «de que no avisen con la misma y mejor precisión de los negocios públicos del Imperio dando cuenta a V.M. con tan expresas noticias como conviene de los intentos del sueco y de los designios del duque de Sajonia, de la disposición de otros príncipes protestantes, de sus fuerzas y de sus negociaciones en la corte del emperador». AGS Estado, legajo 2332.

51 «Relación del viaje que hizo el barón Enrique Paradís de Echayde a Sajonia por mandado del marqués de Cadreita a negocios de SM Católica» BN Mss $10819^{28}$. Vuelve a ser copia de «otra copia que estaba en el archivo del duque de Alburquerque». 
lante, a 10 de noviembre, remitió un informe a don Lope de sus gestiones y éste al rey. Lo llamativo, desde mi punto de vista, es que Díez Aux de Armendáriz parece haber decidido llevar a cabo esta operación, para la que, por propia iniciativa, pidió el beneplácito del emperador a través de Eggenberg (que presidía el Consejo de la Cámara) algo que se antoja sospechoso, máxime si, como Echayde relató al sajón, pensaba realizarla en primera persona ${ }^{52}$. ¿Sería capaz el embajador en Alemania - sin orden expresa de Felipe IV o al menos de su valido - de abandonar Viena y marchar a Dresde en plena guerra para mediar entre el principal elector luterano y el emperador? Es posible, pero me parece poco probable.

Sea como fuere, el caso es que el 31 de agosto don Lope, rendido a la convalecencia, ordenó al barón partir a Sajonia, viaje que se retrasó quince días por problemas con el despacho. Cuando por fin la comitiva (don Enrique no iba solo, sino que llevaba veinticuatro acompañantes y más de una docena de caballos) se puso en movimiento debió detenerse de nuevo a la espera del pasaporte necesario, momento en el que se tuvo noticia de la entrada en guerra de Juan Jorge y de la victoria sueco-sajona sobre los imperiales. Ante el cariz de los acontecimientos, la embajada retornó a Praga en busca de nuevas órdenes con las que partió el 9 de octubre. En esta ocasión solo fueron necesarios diez días para que Paradís llegase a Dresde donde fue recibido en audiencia por el Elector.

Conocemos bastante bien, como decimos, los pormenores de la embajada gracias a los papeles que Echayde remitió a Cadreita, papeles que no se limitaron a la narración de su viaje y entrevista sino que se extendieron a otra documentación colateral de la que nos hubiera sido muy difícil tener conocimiento de no ser por esta vía. Me estoy refiriendo a las respuestas dadas por Sajonia a los enviados de Tilly o a los delegados imperiales en mayo y agosto de 1631, así como escritos referentes a Baviera y sus intentos por explicar el pacto con Francia. Como es lógico no podemos detenernos en todos ellos, (atalayas precisas para ponderar las relaciones «intraimperiales» en plena Guerra de los Treinta Años) pero al menos glosaremos los que hacen referencia directa a la Monarquía.

En el discurso que el barón pronunció ante su dignidad electoral —en alemán, pues no se admitió intérprete - tras las cortesías de rigor se planteó la cuestión clave del viaje: Madrid deseaba que Juan Jorge designara dos personas con amplios poderes para reunirse con otros dos signatarios imperiales $\mathrm{y}$, en presencia de Cadreita, realizar una convención para «allanar los puntos

52 «El excelentísimo señor marqués de Cadreita, embajador residente en corte de su Majestad Cesárea [...] hará cosa de seis semanas que se quiso poner en camino para venir a visitar a Vuestra Alteza en nombre de su Majestad Católica y a significar de su parte el deseo que siempre ha tenido de la paz y tranquilidad de la Germania...» BN mss $10819^{28}$. 
de dificultad que podrá haber». Es decir, la diplomacia española se ofrecía como intermediaria y garante para un futuro acuerdo entre Viena y Dresde. La respuesta sajona no se hizo esperar. Su participación en la guerra había sido la única opción posible frente a los desmanes y abusos de Tilly. Siempre se había confiado en la Casa de Austria pero los excesos del que era general imperial no habían dejado otra alternativa al Elector que pactar con Suecia para oponérsele. Aún así se rogaba al embajador católico que diese su propuesta por escrito y se le inquiría sobre si la misma había sido motivada por la última derrota o era muestra de una política de más amplio alcance. Echayde redactó su discurso y afirmó que:

la intención de la majestad del rey mi señor no la mudaría accidentes causados de una resolución que había tomado el general de la Liga y los que la manejaban sin consentimiento de la Casa de Austria movidos de fines particulares,

desviando la responsabilidad de lo acontecido hacia Baviera ${ }^{53}$.

La respuesta no debió convencer a Juan Jorge - aunque tampoco le disgustó en demasía - y de ahí que decidiera hablar con su invitado en otras condiciones como fueron las de una larguísima cena (que duró más de cinco horas), regada con abundante cerveza e innumerables brindis a la salud de los miembros de ambas familias gobernantes, pero ninguno por el emperador ni la Casa de Austria. Al finalizar, el Elector confesó al barón:

que no sabía que hubiese medio de poderse encaminar su reconciliación con el emperador sin que entrasen en ella los demás sus confederados [...] y que bien podían haberme dejado a mí en paz, pero ahora verá el emperador lo que sus medios juntos le han aconsejado, pero no por eso dejaré de ser muy devoto servidor del rey.

Acabándose aquí la velada. Dos días después, el canciller Guillermo Sunskis acompañado de varios consejeros acudió de nuevo a su posada esta vez para discernir si su comisión "se entendía a tratar de la composición universalmente o sólo particularmente con S.A.», argumentando el embajador que sólo con el Elector ya que en Madrid se pensaba que era necesario primero un arreglo entre Sajonia y el Emperador para poder pasar luego a conversaciones multilaterales. De hecho, la idea que barajaba su majestad católica es que Juan Jorge pudiese convertirse en «árbitro para con los demás» en el caso de

53 BN Mss 10.819. Las afirmaciones de Echayde no hacen honor a la verdad pues Tilly en ese momento no actuaba como general de la Liga sino como comandante en jefe del ejército imperial y, como respondió a los enviados electorales «Él tenía orden de S.M. Cesárea de hacer lo que hacía». No obstante, este argumento ha sido utilizado por cierta historiografía para exonerar a Fernando II de gran parte de su responsabilidad en estos momentos cruciales de la guerra. 
que Francia y Suecia se aviniesen a sentarse a negociar. Con esta propuesta fue de nuevo invitado al palacio ducal Echayde para otra cena rica en connotaciones etílicas y no exenta de momentos de cierta tensión, sobre todo cuando el conde de Mansfelt levantó su copa para brindar por el rey de Suecia, algo a lo que se negó don Enrique argumentando que él no brindaba por enemigos del Emperador máxime cuando nadie había brindado por Fernando II, marchándose a continuación el español a dormir arguyendo que no podía seguir bebiendo ${ }^{54}$. Por fin, al día siguiente le fue dado el despacho y respuesta oficial con la que pudo partir de Dresde el 31 de octubre.

En ella, Juan Jorge relataba de nuevo cómo había sido la intransigencia de los católicos en su afanes por implementar el Edicto de Restitución «que no exceptuaban su Casa que tantos servicios había hecho» la responsable de la actual situación. Recordaba también que se había despojado a su hijo del obispado (secularizado) de Magdeburgo y las atrocidades cometidas tanto por el ejército de Tilly como por las tropas de Aldringen que habían llegado a ocupar «la ciudad más principal de sus estados, llamada Leipzig». En consecuencia, y a pesar de sus esfuerzos en contrario, no había tenido más remedio que pactar con el Sueco y levantar sus banderas, no contra el emperador, sino contra sus agentes en Sajonia. Y, en consonancia con lo dicho, terminaba su respuesta afirmando que:

su dignidad electoral no halla que, en el estado en que las cosas se hallan, pueda tener con una paz particular remedio la nación alemana que está agonizando [...] Ni podría tampoco hacer particular convención estando unido con el rey de Suecia y elector de Brandemburgo. Pero su dignidad electoral, todo lo que pudiere hacer para concluir una universal y segura y buena y estable paz, pondrá todos los medios y poder con mucho gusto como lo ha hecho en el pasado.

Como es obvio, esta conclusión dejaba sin contenido a la embajada española pero su argumentación reforzaba la idea postulada desde Madrid de que, a poco que se cuidase a este Elector, abandonaría el bando anti-imperial propiciando un nuevo equilibrio de fuerzas al norte de Alemania.

No obstante lo expuesto, la opinión que sobre esta embajada se tuvo en la corte de Felipe IV no pudo ser más crítica. En la primera ocasión que, oficialmente, se supo de su existencia (consejo de Estado de 6 de noviembre) se recriminó la forma de llevarla a cabo y su tardanza, si bien se aprobó la iniciativa. Es reseñable que en dicha consulta Olivares no se pronunciase al respecto y fuese Oñate (y conformes con él, todos los demás) quien consultara:

${ }^{54}$ La proverbial capacidad de consumo de cerveza de Juan Jorge era de sobra conocida en la época, de ahí su sobrenombre de «Rey cerveza». Para una cierta revisión de su figura, bastante denostada, GOTTHARD, 2004: 137-147. 
Puédese aprobar al marqués de Cadreita la resolución que tuvo de enviar persona al elector de Sajonia para reconciliarle con el emperador diciéndole que esto hubiera sido mejor más temprano y que debiera haber enviado copia de la instrucción que dio para que sobre los puntos de ella se le pudiera ordenar cómo había de continuar aquella negociación ${ }^{55}$

A los pocos días, el Conde Duque habló por fin al respecto reafirmándose en su idea de que era necesario mandar un embajador directamente a Dresde pues habría de hacer más que el delegado remitido desde Viena ${ }^{56}$ y de paso criticar duramente la gestión de Cadreita con respecto a otros asuntos. Reprensión que continuó al mes siguiente al valorar, con más información, pero todavía escasos de papeles ${ }^{57}$, la embajada en cuestión. Así opinaba don Gaspar el 20 de diciembre:

Al Conde parece que la negociación de Sajonia se ha cometido a persona de poquísima habilidad y maña y aquí procedió harto desatinadamente aunque le sufrimos todos por respeto al duque de Fritland. Puédese escribir allá extrañando el no haber enviado memoria de la proposición y negociación y decir al de Guastalla que acá no pareció este sujeto muy a propósito para este género de ministerio y a Bruneau no hay que escribirle porque es muy estrecho amigo suyo ${ }^{58}$.

Cuando ya a inicios de 1632 se pudo analizar toda la documentación y se valoró en perspectiva la situación en Alemania, los ánimos se calmaron un poco, aunque las ideas claves se mantuvieron. Esto es, se antojaba necesario un relevo de embajadores por lo que se nombró al marqués de Castañeda. No obstante, a pesar de haber sido designado para tal cargo el 12 de marzo, to-

55 AGS Estado, legajo 2332, CCE 6 de noviembre de 1631. Nótese que Oñate da por sentado que la embajada partió motu propio del embajador. Por otro lado, teniendo en cuenta que las instrucciones a Cadreita de acercamiento al elector sajón están fechadas, como hemos visto, a finales de mayo, esto es, recibidas en Viena hacia mediados de julio, tampoco tardó tanto en poner en marcha la expedición.

56 Llama la atención que, a pesar de la vehemencia del valido y el parecer regio («y lo del embajador tengo resuelto y holgara que hubiera partido a Sajonia») nunca se despachó legado a Juan Jorge. Ibidem, CCE, 19 de noviembre de 1631. De hecho, Felipe IV llevaba razón pues, en su resolución a la CCE de 21 de octubre, ya había indicado que se despachase «embajador al duque de Sajonia por la posta de esta corte en derechura».

57 «Si bien en lo de Sajonia es cosa bien rara que no venga copia de la instrucción que le dio el marqués de Cadreita ni lo que Paradís propuso a aquel elector ni lo que le respondió»». AGS Estado, legajo 2332, CCE, 20 de diciembre de 1631. Como sabemos, todos los papeles fueron remitidos por el embajador «a su Majestad con el correo que partió a 11 de diciembre de $1631 »$. BN Mss $10.819^{31}$.

58 A pesar de estas quejas, Echayde no era ningún novato en esas lides. En 1625 había sido remitido desde Viena a Munich por Aytona como negociador. BL Add. 14.003, fol. 176179 con las instrucciones para dicha misión. 
davía a principios de agosto se encontraba en Madrid, para enojo de Felipe IV. Se reconoció la labor de Cadreita en el asunto de Sajonia - no así en otros puntos-y se le animó a seguir intentando «reconciliar a Sajonia al servicio del emperador» frente a los que postulaban una postura de fuerza hacia el Elector. De hecho el consejo en pleno se conformaba en marzo de ese año con el conde de Oñate cuando afirmaba que consideraba mucho más interesante hacer volver a la obediencia al sajón que «debelarle ni quitarle sus estados porque los primero acabaría la guerra y lo segundo la entablaría muy larga $\rangle^{59}$. Por último, ya desde enero, se ordenaba a todos los agentes en Viena que comenzasen a negociar una liga con el emperador «conforme a las órdenes que allá se tienen y ahora van», asunto que tampoco fue fácil y volvió a enfrentar al gobierno central con sus agentes locales. De hecho, el acuerdo al que llegaron Cadreita y Bruneau en Viena el 14 de febrero de 1632 fue deslegitimado por el propio Felipe IV por contener una cláusula propiciadora de la exención de los confederados a compartir los gastos de la guerra con Holan$\mathrm{da}^{60}$ y obligó a replantearse otra vez las negociaciones pero, para entonces, don Lope había abandonado las orillas del Danubio pensando en regresar a las, para él, más seguras aguas del Atlántico.

\section{CONCLUSIONES}

En 1632 las posiciones españolas en Centroeuropa sufrieron muy duros reveses. El fracaso de todas las iniciativas diplomáticas de los últimos años unidos a la expansión sueca y los triunfos holandeses (Maastricht capituló el 23 de agosto) colocaron a la política exterior de Olivares al borde del fracaso total. Sin embargo, fue precisamente este brutal descalabro y en especial el pavoroso avance de Gustavo Adolfo, el que propició un acercamiento más sincero entre las diferentes facciones católicas que permitió reorganizar la lucha y retomar la vía de la conciliación dentro del Imperio. Así, aunque la embajada que hemos visto envío el marqués de Cadreita a Dresde no obtuvo ningún fruto, dejó la puerta abierta a ulteriores acercamientos y permitió al valido, años después, rescatarla como un triunfo ${ }^{61}$. Por otro lado, el miedo al

59 AGS Estado, legajo 2333.

60 El tratado se puede leer en ABREU, 1745: II, 342-349. Lo comenta ALDEA, 1986: LII-LIV. La resolución real tras la CCE 22 de abril de 1632 en AGS Estado, legajo 2333.

61 Como respuesta a una carta de Saavedra Fajardo, a la sazón en Baviera, y para proporcionarle material dialéctico con que refutar las tesis bávaras de que España sólo generaba enemigos al Imperio, Olivares hace un recorrido por todo lo que se ha apoyado a la causa imperial afirmando, entre otras muchas cuestiones: «y la embajada que V.M. envió al duque de Sajonia en aquella ocasión [1631] para procurar su reconciliación y templarle continuándolo V.M. siempre hasta que se consiguió efectivamente» AGS Estado, legajo 2341, CCE pri- 
León del Norte — dueño de Munich desde el 17 de mayo- posibilitó, como decimos, el anhelado acercamiento a Baviera y la colaboración más estrecha entre españoles e imperiales que acabaría fraguando, no sin dificultades, en Nördlingen y que tendría en la paz de Praga su versión sajona. Cuatro años después de la misión de Echayde el horizonte político de Germania era sustancialmente diferente habiéndose cumplido, merced a la labor de embajadores tan experimentados como Oñate, de nuevo en Viena, una parte importante de los objetivos entonces diseñados aunque siempre quedaría pendiente el conseguir involucrar a los aliados en la guerra contra Holanda para mortificación del conde duque y desesperación del cardenal infante ${ }^{62}$. Con todo, la documentación española recoge para todos estos años una constante y es la continua frustración que la alianza con el Imperio produce. La sensación de traición - no es lugar éste para dirimir si fundada o no- y nula correspondencia por parte de Fernando II (y más adelante Fernando III) es recurrente en todas las consultas del Consejo de Estado ${ }^{63}$. Madrid se desgañitaría intentando hacer ver a sus primos que los enemigos de uno lo eran del otro, pero Viena, una vez superado el pánico sueco no secundó esta opinión. Cuando, a raíz de la crisis de 1640 los subsidios dejaron de afluir tan liberalmente desde el sur al norte de Europa, el distanciamiento se ensanchó para beneficio de Francia, cumpliéndose entonces los más lúgubres vaticinios que don Gaspar de Guzmán había pronosticado ${ }^{64}$. Don Lope Aux de Armendáriz, mientras, desde su alejado gobierno virreinal, arreglaba cuentas con la Real Hacienda intentando rescatar parte del capital gastado en su breve pero intensa embajada a Alemania ${ }^{65}$.

mero de diciembre de 1640. Por otro lado, el acercamiento a Sajonia no es una iniciativa exclusiva de Olivares, ya desde tiempos de Felipe II, Dresde era considerada como una potencial - y deseada - aliada.

62 De este tema nos ocupamos en profundidad en la edición que, junto a sir John Elliott, estamos preparando de la correspondencia entre estos dos hombres y que saldrá publicada en breve por Marcial Pons y el Centro de Estudios Europa Hispánica.

63 Se ha ocupado de ello en profundidad y con rigor ERNST, 1991. Para ofrecer una mirada ponderada a las relaciones entre las dos ramas de la Casa de Austria sería necesario un espacio mucho más amplio del que aquí disponemos. Algo de ello nos gustaría mostrar en nuestro próximo libro sobre la Guerra de los Treinta Años que publicará la editorial Síntesis.

64 «Los franceses tientan la guerra para, si sale bien, arruinar la casa de V.M. y seguilla hasta su último exterminio [...] Conviene abrir los ojos y hacer que los abran el emperador y el rey de Hungría procurando a cualquier precio —o por los ministros o por los príncipesganar precisamente la inseparable unión sin que se hable por dos bocas». voto de Olivares en CCE de 27 de noviembre de 1635. AGS Estado, legajo 2336.

65 En septiembre de 1637 se expedía una real cédula para que se le pagasen 97.147 reales en plata «que se le deben en propinas y de sueldo de embajador en Alemania y otras cosas». Claro que dos años después las deudas para con él ascendían a casi 300.000 reales. Cfr. AGI Indiferente, 434, 1.8 f. 301-302v y 435, 1.9, f. 217v-220. 


\section{BibLiOgRAFÍA}

Abreu y Bertodano, José, Coleccion de los tratados de paz, alianza, neutralidad, garantia ... hechos por los pueblos reyes y principes de España con los pueblos, reyes, principes, republicas y demás potencias de Europa ...: desde antes del establecimiento de la monarchia gothica hasta el feliz reynado del rey N.S.D. Fernando VI, Parte II, Madrid, Juan de Zúñiga, Antonio Marín y la viuda de Peralta, 1745.

Albrecht, Dieter, Die auswärtige Politik Maximilians von Bayern, 1618-1635, Göttingen, Vandenhoeck und Ruprecht, 1962.

Alcalá-Zamora y Queipo de Llano, José, España, Flandes y el Mar del Norte, Madrid, Centro de Estudios Constitucionales, 2001.

Aldea Vaquero, Quintín, España y Europa en el siglo XVII. Correspondencia de Saavedra Fajardo, Madrid, CSIC, 4 vols., 1986-1991.

Álvarez de Toledo, Cayetana, Juan de Palafox, obispo y virrey, Madrid: CEEHMarcial Pons, 2011.

Amadori, Arrigo Armando, Política americana y dinámicas de poder durante el valimiento del Conde-Duque de Olivares, (1621-1643), Tesis Doctoral Inédita, UCM, 2011.

Andrés Tovar, Alfonso, «Cadreita. Señores y marqueses (1124-1644)», Príncipe de Viana, nº 64 (Pamplona, 1956), 331-357.

Barrio Gozalo, Maximiliano, «El señorío de Cadreita en la época moderna: aproximación al estudio de su economía y de la renta señorial», Príncipe de Viana, 59/213 (Pamplona, 1998), 197-214.

Beladiez, Emilio, España y el Sacro Imperio Romano Germánico. Wallenstein (1583-1634), Madrid, Prensa Española, 1967.

Bireley, Robert, Religion and Politics in the Age of the Counterreformation. Emperor Ferdinand, William Lamormaini (S.I.) and the Formation of Imperial Policy. Chapel Hill: University of North Carolina Press, 1981.

Bireley, Robert, The Jesuits and the Thirty Years War. Kings, Courts and Confessors, Cambridge, Cambridege University Press, 2003.

Carrocera, Fray Buenaventura, «El P. Diego de Quiroga, diplomático y confesor de reyes», Estudios franciscanos, 50 (Madrid, 1947), 71-100.

Elliott, John H., El Conde-Duque de Olivares. El político en una época de decadencia, Barcelona, Crítica, 1990.

Elliott, John H. y De la Peña, José F., Memoriales y Cartas del Conde Duque de Olivares (ed. ampliada a cargo de John Elliott y Fernando Negredo), Madrid, CEEHMarcial Pons, 2013.

Ernst, Hildegard, Madrid und Wien 1632 1637. Politik und Finanzen in den Beziehungen zwischen Philipp IV und Ferdinand II, Münster, Aschendorff Verlag, 1991.

Esteban Estríngana, Alicia, Madrid y Bruselas. Relaciones de gobierno en la etapa postarchiducal (1621-1634), Lovaina, Leuven University Press, 2005. 
Fernández Álvarez, Manuel: D. Gonzalo Fernández de Córdoba y la guerra de sucesión de Mantua y Monferrato, 1627-29, Madrid, CSIC, 1955.

Fernández Duro, Cesáreo, Armada española, Madrid, sucesores de Ribadeneira, 1895.

Gotthard, Axel, ««Politice seint wir Bäpstisch». Kursachsen und der deutsche Protestantismus im frühen 17 Jahrhundert», Zeitschrift für Historische Forschung, 20 (1993), 275-319.

Gotthard, Axel, «Johann Georg I. 1611-1656» en Kroll, Frank-Lothard (ed.), Die Herrscher Sachsens, Munich, C. H. Beck Verlag, 2004, 137-147.

Günter, Heinrich, Die Habsburger-Liga (1625-1635), Berlín, E. Ebering, 1908.

Gui, Francesco, I Gesuiti e la rivoluzione boema. Alle origini della guerra dei trent'anni, Milán, FrancoAngeli, 1989.

Hanke, Lewis, Los virreyes españoles en América durante el gobierno de la Casa de Austria, Madrid, Atlas, IV, 1977.

Israel, Jonathan, Razas, clases sociales y vida política en el México colonial, 16101670, México, Fondo de Cultura Económica, 1980.

Kraus, Andreas, Maximilian I. Bayerns Grosser Kurfürst, Graz, 1990.

Krumenacker, Yves, La guerre de Trente Ans, París, Ellipses, 2008.

Labrador Arroyo, Félix, «La organización de la casa y el séquito de la reina de Hungría en su jornada al Imperio en 1629-30» en Martínez Millán, José y González Cuerva, Rubén (coords.), La Dinastía de los Austria. Las relaciones entre la Monarquía Católica y el Imperio, vol II, Madrid, Polifemo, 2011; 801-836.

Lohmann Villena, Guillermo, Los americanos en las órdenes militares, 2 vols. Madrid, CSIC, 1993 [1 ${ }^{\mathrm{a}}$ ed. 1947].

Mann, Golo, Wallenstein, Barcelona, Grijalbo, 1978.

Mann, G. y Heuss, A. (dirs.), De la Reforma a la Revolución, Madrid, Espasa Calpe, 1988.

Negredo del Cerro, Fernando y Villalba Pérez, Enrique, «Los jesuitas y la Monarquía Hispánica en el contexto de la Guerra de los Treinta Años (1625-1635)» Hispania Sacra, LXVII, 136 (2015), 49-80.

Pagés, Georges, La Guerre de Trente Ans, 1618-1648, París, Payot, 1949.

Parker, Geoffrey, La Guerra de los Treinta Años, Barcelona, Crítica, 1984.

Polisensky, Joseph V., The Thrity Years War, Berkeley, University of California Press, 1971.

Polisensky, Joseph V., War and Society in Europe, 1618-1648, Cambridge University Press, 1978.

Raviola, Blythe Alice, «Madrid, Viena, Mantua y Turín: Relaciones diplomáticas entre cortes y lugares de poder en torno a las guerras del Monferrato» en Martínez Millán, José y González Cuerva, Rubén (coords.), La Dinastía de los Austria. Las relaciones entre la Monarquía Católica y el Imperio, vol II, Madrid, Polifemo, 2011; 953-972. 
Reeve, John, «Quiroga's Paper of 1631: a missing link in Anglo-Spanish diplomacy during the Thirty Years War» English Historical Review, no 101 (1986): 913-926.

Ródenas Vilar, Rafael, La política europea de España durante la Guerra de Treinta Años (1624-1630), Madrid, CSIC, 1967.

Sanz Camañes, Porfirio, Diplomacia hispano-inglesa en el siglo XVII, Cuenca, Ediciones de la Universidad de Castilla-La Mancha, 2002.

Stradling, Robert A., «Olivares and the origins of the Franco-Spanish War, 16271635» English Historical Review, 101 (Oxford, enero 1986), 68-94.

Straub, E., Pax et Imperium. Spaniens Kampf um seine Friedensordnung in Europa zwischen 1617-1635. Paderborn, Ferdinand Schöningh, 1980.

Visceglia, $\mathrm{M}^{\mathrm{a}}$. Antonietta, «Convergencias y conflictos. La Monarquía Católica y la Santa Sede (siglos XV-XVIII)», Studia Historica 26 (Salamanca,2004): 155-190.

Wilson, Peter H., «The Causes of the Thirty Years War 1618-1648» English Historical Review, 123 (Oxford, junio 2008), 554-586.

Wilson, Peter H., Europe's Tragedy. A History of the Thirty Years War, Londres, Penguin Books, 2009.

Recibido: 21/09/2013

Aceptado: 15/04/2014 